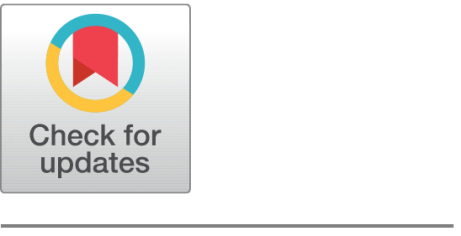

G OPEN ACCESS

Received: $10-04-2020$

Accepted: $12-05-2020$

Published: 17-06-2020

Editor: Dr. Natarajan Gajendran

Citation: Thirumagal N, Jeyakumari AP (2020) Photocatalytic and antibacterial activity of silver nanoparticles (AgNPs) using palm (Borassus flabellifer L.) water ( Pathaneer ). Indian Journal of Science and Technology 13(18): 1856-1866. https://doi.org/ 10.17485/IJST/v13i18.222

* Corresponding author. A Pricilla Jeyakumari

Department of Physics, Thiruvalluvar Government Arts College, Rasipuram, Tamil Nadu, India

pricilla1510@gmail.com

Funding: None

Competing Interests: None

Copyright: (c) 2020 Thirumagal, Jeyakumari. This is an open access article distributed under the terms of the Creative Commons Attribution License, which permits unrestricted use, distribution, and reproduction in any medium, provided the original author and source are credited.

Published By Indian Society for Education and Environment (iSee)

\section{Photocatalytic and antibacterial activity of silver nanoparticles (AgNPs) using palm (Borassus flabellifer L.) water ( Pathaneer)}

\author{
N Thirumagal ${ }^{1}$, A Pricilla Jeyakumari ${ }^{1}{ }^{*}$ \\ 1 Department of Physics, Thiruvalluvar Government Arts College, Rasipuram, Tamil Nadu, \\ India
}

\section{Abstract}

To evaluate the photocatalytic and antibacterial activity of a biologically synthesized AgNPs mediated by palm (Borassus flabellifer) water against human pathogens. It is a potential candidate for preparing nanomedicine for constipation. $1 \mathrm{mM}$ of $\mathrm{AgNO}_{3}$ is prepared and mixed with an appropriate volume of Pathaneer and the reaction was made up to $100 \mathrm{ml}$. The AgNPs were characterized by X-ray diffraction, FT-IR, UV-Vis analysis and HRTEM. The photocatalytic property and the antibacterial activity were carried out for the prepared AgNPs. The powder X-ray diffraction investigation reveals the FCC structure of AgNPs with a crystalline size of $27 \mathrm{~nm}$ and a lattice strain of 0.4283 . FT-IR confirms the presence of $\mathrm{Ag}^{+}$from UV-Vis, the energy band gap was found to be $2.92 \mathrm{eV}$. HRTEM was used to calculate the diameter of AgNPs as 5-10nm. In Borassus flabellifer, the percentage degradation state of AgNPs was estimated as $87 \%$ at 180 minutes. AgNPs derived from Pathaneer have a large impact as antibacterial in the biomedical field. Since the aggressive chemicals are not involved in the preparation of AgNPs, it is used as an alternated biomedicine to reduce the toxicity of AgNPs and the photo degradation efficiency is high hence suitable for solar cells as well.

Keywords: AgNPs; HRTEM; photocatalytic; antibacterial activity

\section{Introduction}

Silver-based nano compounds are used in chemical ${ }^{(1,2)}$, physical $^{(3,4)}$ and biological process ${ }^{(5,6)}$. Vander Horst et al. ${ }^{(7)}$ have reported electrochemical sensor application of silver nanoparticles. Green biosynthesis of AgNPs is applied as an antibacterial agent and a catalyst ${ }^{(8)}$. In biological method, several parts of the plant are used as a reducing agent to attain silver nanoparticles ${ }^{(9-13)}$. Among various metal nanoparticles, silver has attracted more attention because of their antibacterial activity.

Pathaneer obtained from the Palmyra sap usually involves tapping the top shoots and collecting the saturated juice in hanging clay pots overnight from palm trees. These clay pots are coated with calcium carbonate to reduce fermentation. 
This sweet water is called Pathaneer which is available only in summer. It is delicious, contains high nutrition, unfermented juice from Palmyra palm tree reduces body heat. It is one of the excellent beverages for beating the summer heat. Pathaneer contains nutrients like electrolytes, calcium, vitamin B, vitamin C, Phosphate, low calories, low fat etc.

In this work, the synthesized AgNPs from Pathaneer were characterized structurally and optically by X-ray, FTIR, Photoluminescence, Dynamic light scattering, Scattering electron microscope, Transmission electron microscope, UV-Vis, photoluminescence and photo catalytic process. Its antibacterial activities are also studied.

\section{Experimental}

\subsection{Materials and Method}

\subsubsection{Materials required}

Pathaneer were collected from the palm garden of Vaiyappamalai near Rasipuram, Namakkal District, Tamilnadu. AgNo 3 were purchased from Mercury's scientific, Salem, Tamilnadu.

\subsubsection{Preparation of extract}

Pure Pathaneer were collected from the palm garden, then it was filtered with the help of filtration set and the filtered water was collected and immediately used for synthesis.

\subsubsection{Synthesis of silver nanoparticles}

$10 \mathrm{ml}$ of Pathaneer was taken into two different flask and $90 \mathrm{ml}$ of $5 \mathrm{mM}$ aqueous AgNPs was added carefully in each flask. It was enclosed with aluminum foil and then the solution was heated in the water bath at $60^{\circ} \mathrm{C}$ for $30 \mathrm{~min}^{(14)}$. After $30 \mathrm{~min}$ the colour changed from white to dark brown. This indicates the formation of AgNPs ${ }^{(15)}$. The supernatant was centrifuged for $20 \mathrm{~min}$ and the pellets were collected and kept in microwave oven at $60^{\circ} \mathrm{C}$ for $15 \mathrm{~min}$ in order to set AgNPs.

\subsection{Characterization Methods}

The purified silver nanoparticles were frozen, and dried to evaluate their crystalline structure, the crystallite size of the nanoparticles using X-ray diffractometer (Bruker D8 Advance, Germany) equipped with CuK $\alpha$ radiation $(\lambda=1.5418 \AA$ ) in the $2 \theta$ range from $20^{\circ}$ to $80^{\circ}$. The crystalline size of these silver nanoparticles was calculated by using the Debye Scherer's equation. FT-IR analysis of the material was carried out by JASCO 460 PLUS FT-IR spectrometer in the range of $4000-400 \mathrm{~cm}^{-1}$. The synthesized AgNPs sample was dried and ground with $\mathrm{KBr}$ pellets and analyzed. The various modes of vibrations were identified to determine the different functional groups present in the AgNPs. The particle morphology, shape and size of synthesized AgNPs were analyzed by Field Emission Scanning electron microscope (SIGMA HV -Carl Zeiss with Bruker Quantax 200Z10 EDS Detector). In this experiment, the thin film of the sample was deposited on the carbon-coated copper grid. EDAX was carried out to confirm the elements present in the biosynthesized silver nanoparticles. The surface morphology, shape and size of the synthesized AgNPs were measured by HRTEM (Jeol/JEM 2100, LaB6, 200kV). The size distribution of bioreduced silver nanoparticles was measured using DLS (Micromeritics, Nano Plus). Biosynthesized AgNPs were analyzed by using UVVis spectrum recorded by Perkin Elmer Lambda35 in the range 190-1100nm. The fluorescence spectrum was measured on a Perkin Elmer Lambda 45 in the range of 200-900 $\mathrm{nm}$.

\subsection{Antibacterial assay}

The antibacterial activities of AgNPs were tested against both gram positive and gram negative bacteria. Medical isolates of Staphylococcus aureus, Escherichia coli were sub-cultured in nutrient broth for $24 \mathrm{~h}$ at $37^{\circ} \mathrm{C}$. This study was carried out in agar by well diffusion method ${ }^{(16)}$. AgNPs, $\mathrm{AgNo}_{3}$, Leaf extract was mixed with Milli-Q water. For positive control standard antibiotic Lysol (1\%) was used and Negative control Milli-Q water alone used. After $24 \mathrm{~h}$ of incubation at $37^{\circ} \mathrm{C}$, the zone of inhibition was determined.

\subsection{Statistical analysis}

Each value is the mean of three replications each $(n=3)$. Statistically, the means of the three experiments were not significantly different $(\mathrm{P}<0.05)$. Means in the same column with different letters are significantly different at $(\mathrm{P}<0.05)$ in accordance with Fisher's least significant difference test. The statistical result shows that the synthesized silver nanoparticles are the potential candidate for enhancing antibacterial property. 


\subsection{Photo catalytic activity}

The photo catalytic activities of synthesized AgNPs were evaluated using methyl blue under sunlight irradiation. $2.5 \mathrm{mg}$ of prepared AgNPs was added to $100 \mathrm{~mL}$ of a1 $\mathrm{mg} / \mathrm{L} \mathrm{MB}$ aqueous solution. Stirring the solution for $30 \mathrm{~min}$ in a dark to bring the AgNPs to constant equilibrium in the mixture. Then kept the mixture in sunlight for 2-2.30 h. The sample was collected at regular intervals (for every $30 \mathrm{~min}$ ). The collected sample were filtered and centrifuged to ensure photo of the dye.

\section{Result and discussion}

\subsection{Structural and Morphological study}

The crystalline nature of the newly prepared AgNPs was confirmed using powder XRD analysis as shown in Figure 1. There were three intense diffraction peaks found at $2 \theta$ values $38.55^{\circ}, 44.43^{\circ}$ and $64.29^{\circ}$ corresponding to (111), (200), and (220) planes respectively, for the face entered cubic structures of silver (JCPDS, File no: 04-0783). The presence of other peaks at $2 \theta$ values corresponds to (211), (122), and (231) diffraction peaks for orthorhombic structure of $\mathrm{AgNo}_{3}$ (JCPDS, File no: 43-0649) shows the presence of untreated $\mathrm{AgNo}_{3}$ as impurity. The powder XRD analysis pattern clearly shows that the synthesized silver nanoparticles were crystalline in nature.

For FCC structure of the lattice parameter (a) can be calculated by the measured values of the d spacing of the (111) planes using the following equation.

$$
d_{h k l}=a / \sqrt{h^{2}+k^{2}+l^{2}}
$$

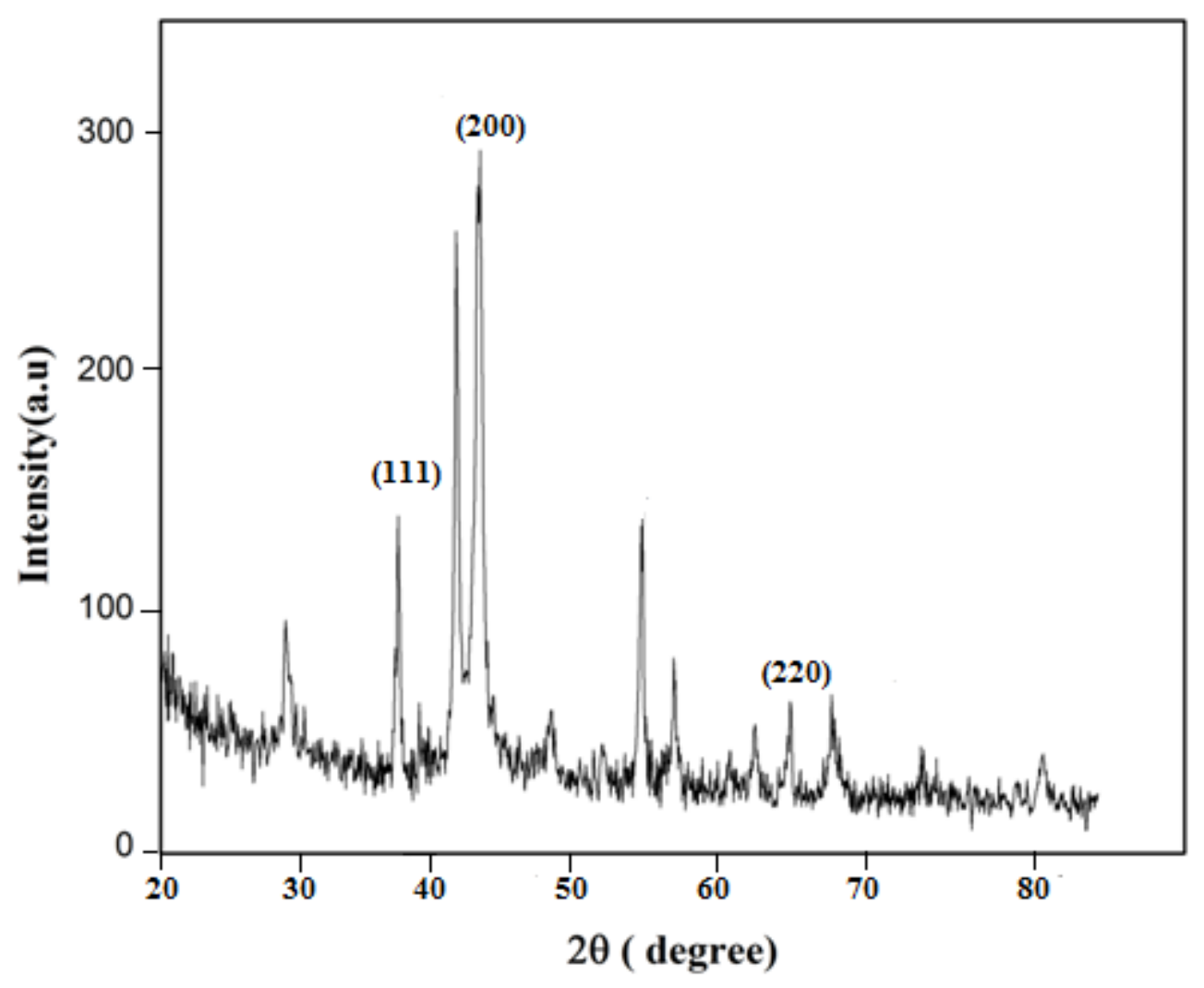

Fig 1. Powder XRD pattern of synthesized AgNPs

Where, $\mathrm{a}$ is a lattice parameter $\mathrm{h}, \mathrm{k}$, and $\mathrm{l}$ are Miller indices of the crystalline graphic plane. The calculated value of $\mathrm{a}=$ $4.080^{\prime}$ is very well agreed with the standard JCPDS File no: 04-0783 for silver nanocrystal. The average crystallite size (D) was 
calculated using Debye-scherrer's formula. The average crystalline size is around $27 \mathrm{~nm}$.

$$
D=K \lambda / \beta \cos \theta
$$

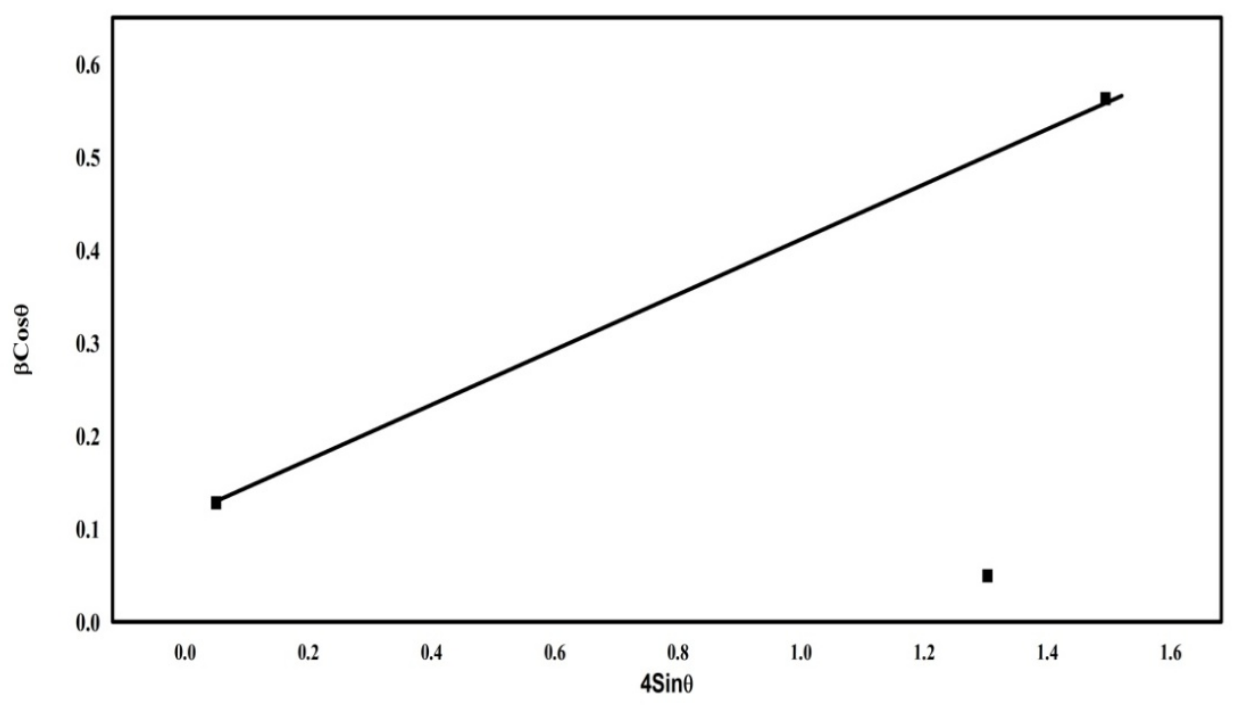

Fig 2. The W-H plot of AgNPs

Willamson- Hall method (W-H) is suggested to calculate the microstrain of the prepared AgNPs using the modify Scherer's equation ${ }^{(17)}$.

$$
\beta \cos \theta=(K \lambda / D)+(4 \in \sin \theta)
$$

The non zero slope of the strain ( Figure 2) shows that the presence of lattice strain, due to its strong dislocation density, which enhances the properties of the material ${ }^{(18)}$. The microstrain of AgNPs is found to be 0.4282 from W-H plot.

\subsubsection{Dislocation density $(\delta)$}

The dislocation density $(\delta)$ is calculated using the relation.

$$
\delta=1 / D^{2}
$$

The number of unit cells (n) is estimated from

$$
n=(4 / 3)(D / 2)^{3}(1 / V)
$$

Where $\mathrm{V}$ is the volume of the unit cell.

\subsubsection{Morphology Index}

The Morphology Index (MI) is calculated from full wave half width maxima [FWHM] of powder XRD. MI is obtained using the relation ${ }^{(19)}$.

$$
M I=F W H M_{h} / F W H M_{h}+F W H M_{p}
$$


Where $\mathrm{FWHM}_{h}$ was the greatest FWHM value achieved from peaks, FWHMp was the value of particular peak's FWHM. The calculated Morphology index values are given in Table 1.

\subsubsection{Relative Percentage}

The Relative Percentage Error (RPE) ${ }^{(19)}$ is calculated by

$$
P R E=\left(\left|Z_{H}-Z\right| / Z\right) X 100
$$

Where $\mathrm{Z}_{H}$ is the experimental d-values in the XRD pattern and $\mathrm{Z}$ is the standard $\mathrm{d}$-values in JCPDS data. The calculated RPE values are shown in Table 1.

Table 1. X-ray Diffraction analysis of FCC Silver nanoparticles

\begin{tabular}{llllccc}
\hline $\begin{array}{l}2 \theta^{\mathrm{o}} \\
\text { degree }\end{array}$ & $\begin{array}{l}\mathrm{d}- \\
\text { spacing } \\
\left({ }^{\prime}\right)\end{array}$ & $\begin{array}{l}\text { Crystalline size } \\
\mathrm{D}(\mathrm{nm})\end{array}$ & $\begin{array}{l}\text { Dislocation Density } \\
\left(\mathrm{x} 10^{14} \text { lines } / \mathrm{m}^{2}\right)\end{array}$ & $\begin{array}{l}\text { Number of } \\
\text { unitcells }\left(\mathrm{x} 10^{6}\right)\end{array}$ & $\begin{array}{l}\text { Morphology } \\
\text { index (MI) }\end{array}$ & $\begin{array}{l}\text { Relative Percentage } \\
\text { error (RPE) }\end{array}$ \\
\hline 38.55 & 2.3528 & 14.274 & 4.900 & 7.8824 & 0.5 & 0.7 \\
44.43 & 1.9557 & 34.9156 & 8.911 & 11.8545 & 0.8364 & 0.1 \\
64.29 & 1.5229 & 27.021 & 9.801 & 8.8294 & 0.6666 & 0.4 \\
\hline
\end{tabular}

\subsection{FTIR analysis}

The stretching vibrations are generally absorbed in the spectral range of $3500 \mathrm{~cm}^{-1}$ to $500 \mathrm{~cm}^{-1}$ by FTIR spectrum ( Figure 3). In the present study a strong band at $3449 \mathrm{~cm}^{-1}$ and $3392 \mathrm{~cm}^{-1}$ are due to the stretching modes of $-\mathrm{OH}$ group. The band at $2359 \mathrm{~cm}^{-1}$ indicates C-N stretching vibration of Nitriles ${ }^{(19)}$. The band at $1696 \mathrm{~cm}^{-1}$ indicates amide I bond of proteins due to carbonyl group. The vibrational mode at $1498 \mathrm{~cm}^{-1}$ originates from amide linkage. A strong peak at $558 \mathrm{~cm}^{-1}$ are due to the metallic bond $\mathrm{Ag}+{ }^{(20-22)}$.

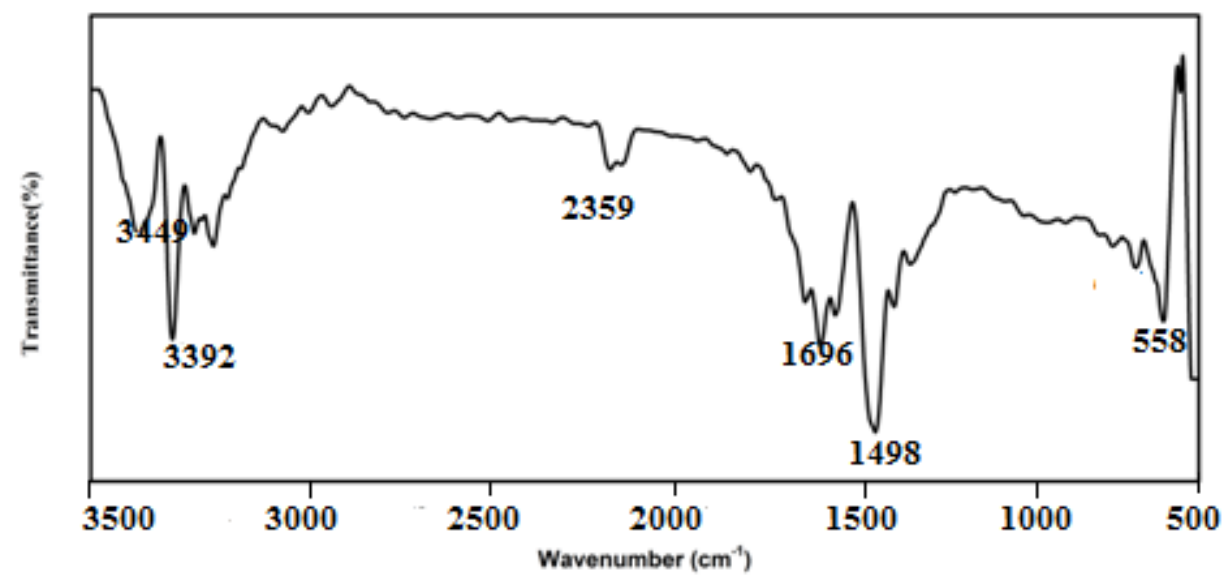

Fig 3. The FTIR spectrum of synthesized AgNPs

\subsection{Morphology studies}

FESEM shows the morphology of silver nanoparticles ( Figure 4 ). The obtained crystalline size is found to be $27 \mathrm{~nm}$, it is closely agreed with powder XRD result. EDX ( Figure 5) shows the chemical composition present in the sample. HRTEM was used to characterize the shape, surface morphology of AgNPs. The Figure 6(6a) shows that the particles are in spherical shape and 
the diameter of the particles are in the range of 5-10 nm and they are polydispersed. Figure 6 (6b) shows that selective electron diffraction(SAED) pattern of AgNPs, whereas white spots indicate that the AgNPs are crystalline in nature. The average number of atoms per nanoparticle was calculated by using the formula given below ${ }^{(23)}$.

$$
\begin{aligned}
& \left.N=\left[\pi_{p} D^{3}\right) /(6 M)\right] * N_{A} \\
& N=\left[\left(\pi\left(1.05 \times 10^{-20}\right)(11)^{3}\right) /(6(108))\right] * 6.022 \times 10^{23} \\
& =4.078 \times 10^{4} \text { atoms } / N P
\end{aligned}
$$

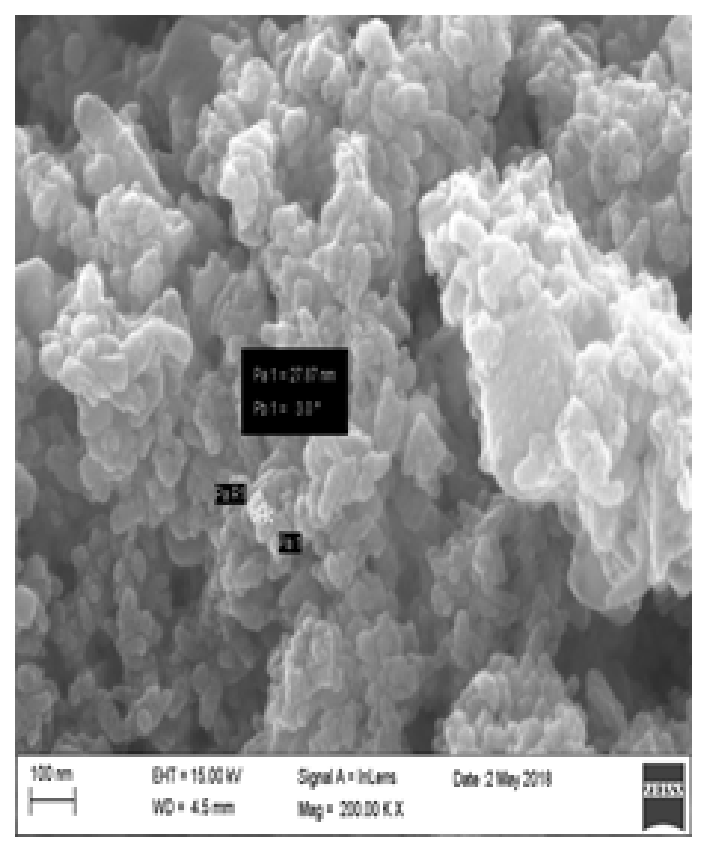

Fig 4. FESEM image of AgNPs

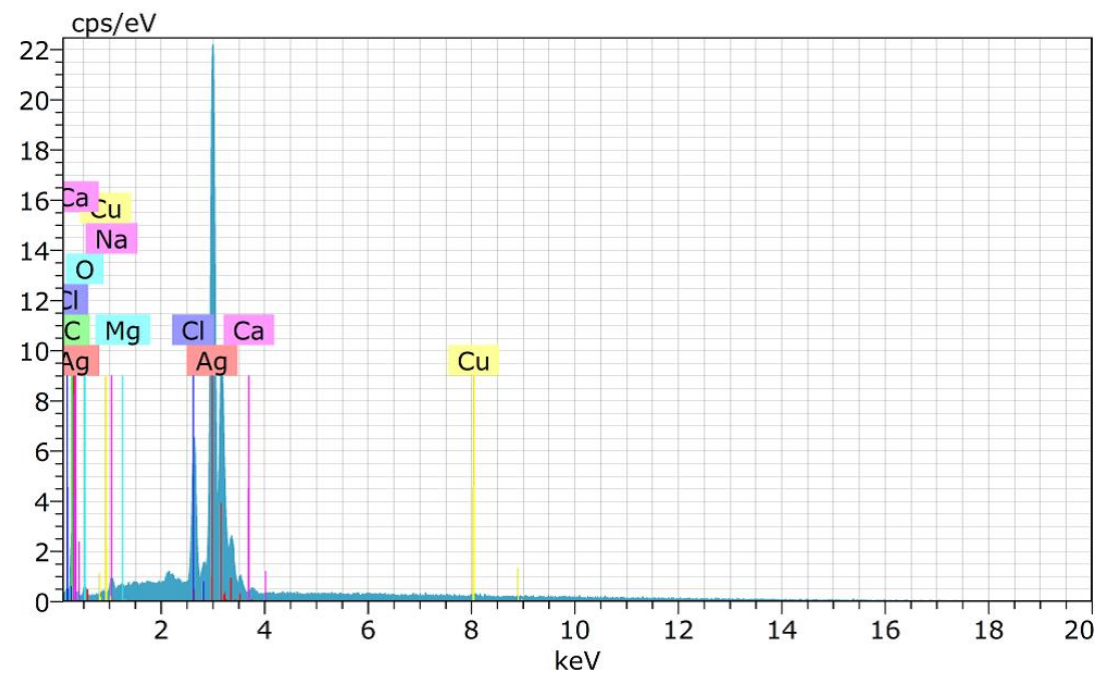

Fig 5. EDX spectrum of AgNPs 

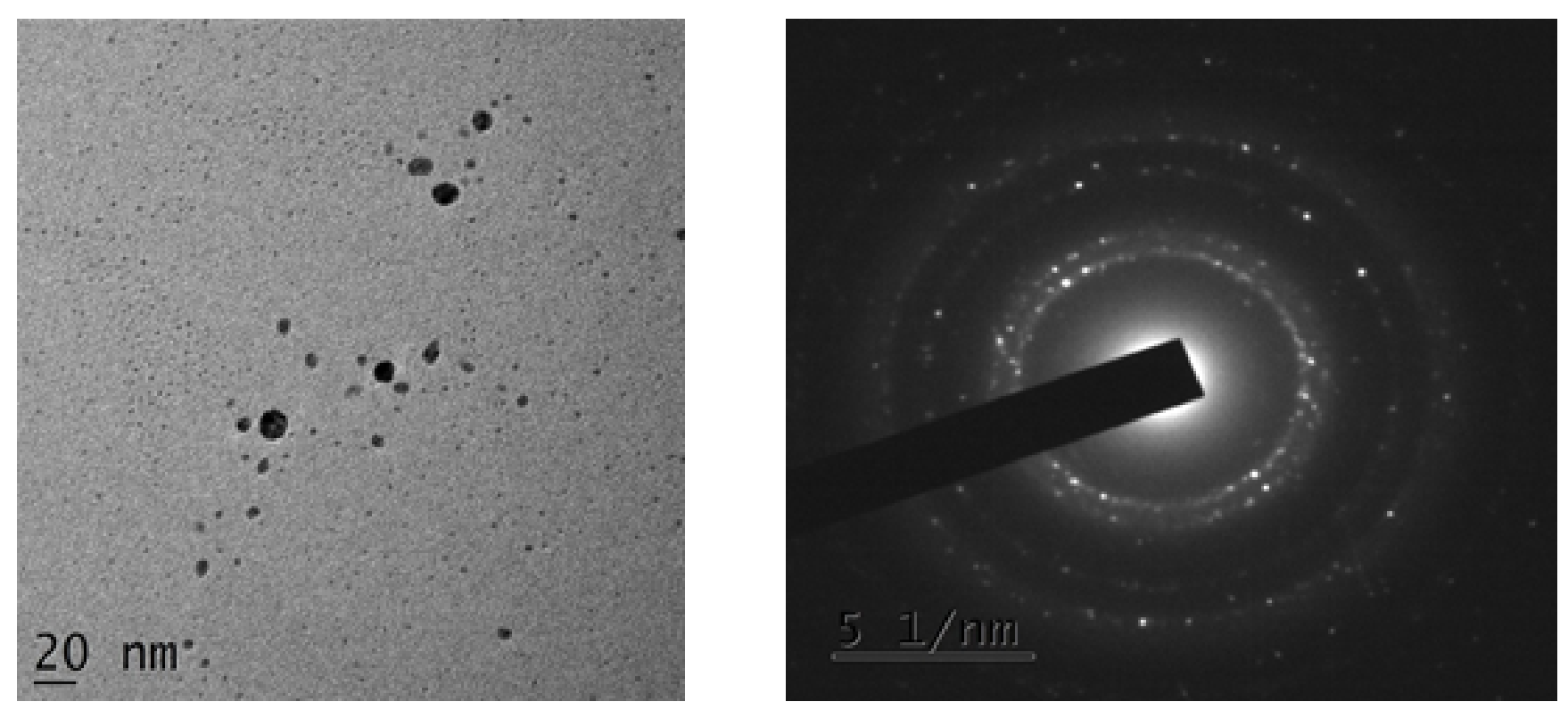

Fig 6. a. TEM image of AgNPs. b. SAED pattern of AgNPs

\subsection{Fluorescence studies}

The fluorescence spectrum of AgNPs were recorded in the range of $200-900 \mathrm{~nm}$. From the Figure 7, four emission peaks obtained at 367,383,523 and $597 \mathrm{~nm}$ respectively. Out of the above peaks 367 and $383 \mathrm{~nm}$ represent the high intensity emission in the blue region and the 523,597 $\mathrm{nm}$ peaks are in green emission region. Over all the peaks lies in the visible region, the material might be suitable for optoelectronic device fabrication ${ }^{(24)}$.

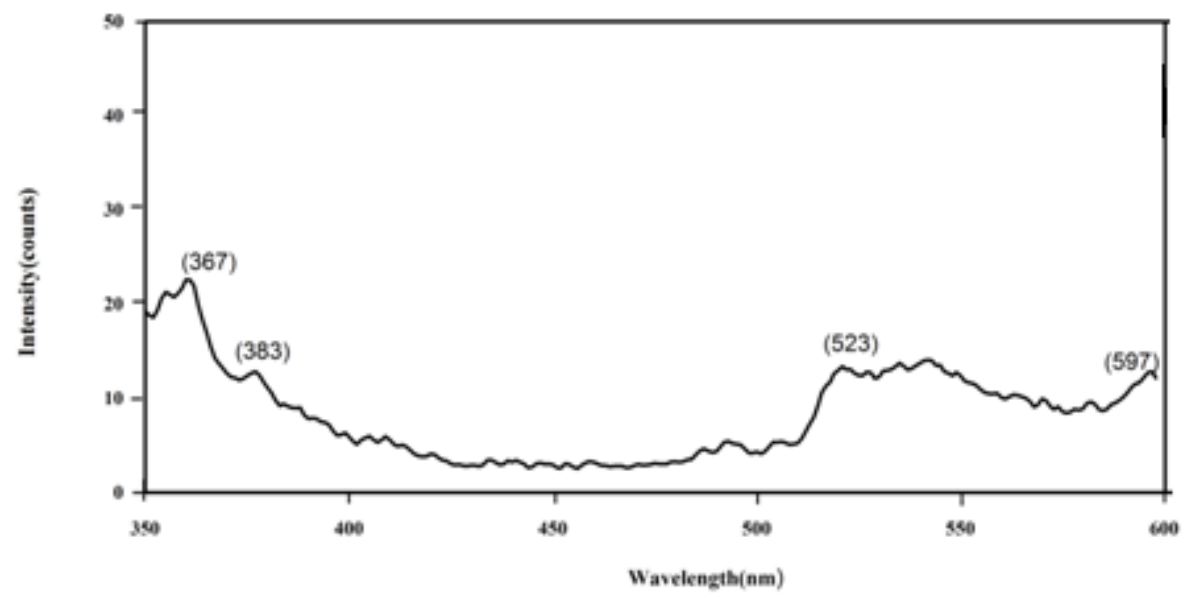

Fig 7. The FTIR spectrum of synthesized AgNPs

\subsection{Dynamic Light scattering studies (DLS)}

Dynamic light scattering technique can be used to determine the average particle size of AgNPs. In the present work, the synthesized silver nanoparticles are polydispersed in nature as shown in the Figure 8 with the average particle size of $12.4 \mathrm{~nm}$. 


\section{Intensity Distribution}

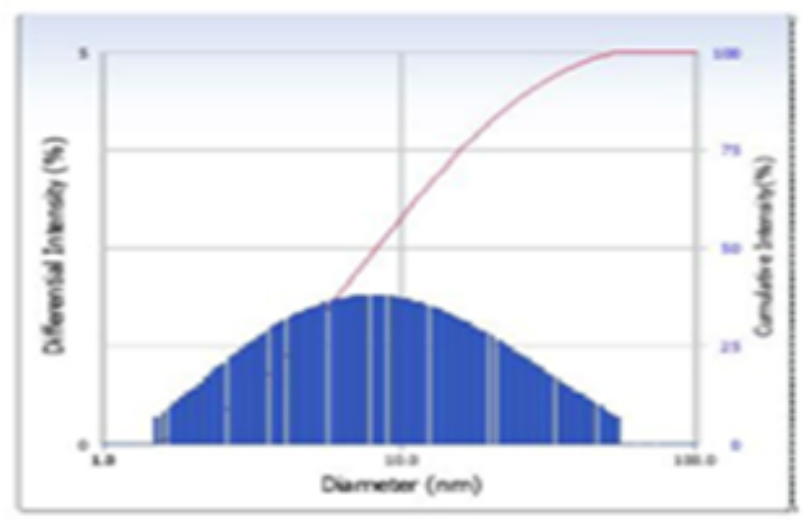

Fig 8. The DLS pattern of synthesized AgNPs using pathaneer

\subsection{Linear Optical studies}

Optical properties of prepared AgNPs were examined using UV-Vis absorption spectrum ( Figure 9). The AgNPs absorption strongly at $436 \mathrm{~nm}$. This excitation peak is due to the surface plasma resonance. The optical energy band gap is calculated by using the following equation

$$
\alpha h v=A\left(h v-E_{g}\right)^{n}
$$

Where $\alpha$ is the absorption co-efficient, $\mathrm{h} v$ is the photon energy, $\mathrm{E}_{g}$ is the optical energy band gap and $\mathrm{A}$ is a constant. Where $\mathrm{n}$ is the parameter involved in the transition process. If $\mathrm{n}=2$, it will be for directly allowed transition and $\mathrm{n}=1 / 2$ for indirect transition. The calculated value of the energy gap is $2.92 \mathrm{eV}$ which is lower compared with the result reported by Narental Budhiraja et al. $(4.27 \mathrm{eV})$, particle size decreases as the bandgap increases, it may be due to the quantum effect ${ }^{(25)}$.

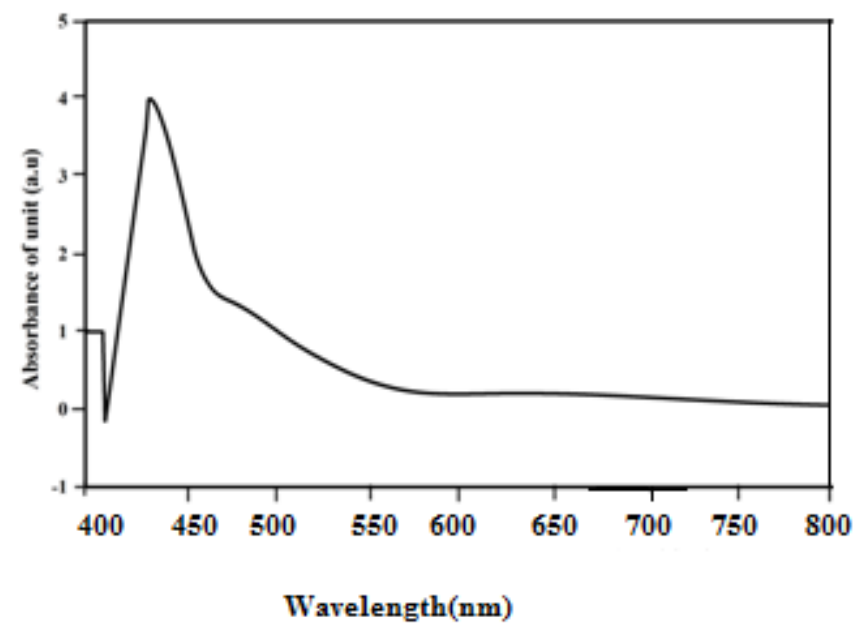

Fig 9. The UV-Vis Spectrum of AgNPs 


\subsection{Photocatality Mechanism}

The mechanisms of photo catalytic degradation of methyl blue under sunlight can be as shown in the Figure 10. Metal nanoparticles carry electron from the donor to the acceptor, the absorbed photons excited the valance band electrons to conductions band, due to the reduction of decomposition of the dye molecules and hence conduction band electrons. On the other hand during the process when the sunlight is absorbed and $\operatorname{ROS}\left(\mathrm{O}_{2}, \mathrm{OH}^{-}, \mathrm{H}_{2} \mathrm{O}_{2}\right)$ radicals are formed that leads to cleaning its surfaces by itself. Photo catalytic activity of AgNPs was determined by deoxidation of MB under the natural energy resources sunlight for 2 to $2.30 \mathrm{hrs}$. At first the degradation in the existence of silver nanoparticles was absorbed visually the intensity of colour gradually decreases with increase in time, colour changes from dark blue to pale blue, the intensity peak absorbed at $647 \mathrm{~nm}$. Thus the result shows ( Figure 8) that the effective catalytic degradation of AgNPs in the presence of sunlight is faster. It was observed that the intensity of peaks decreases with increase in the natural resource sunlight irradiation time. The percentage of degradation state of AgNPs was estimated as $87 \%$ at 180 minutes. Photo catalytic reaction mechanisms are as follows:

AgNPs $\left(\mathrm{e}^{-} \mathrm{CB}\right)+\mathrm{O}_{2} \rightarrow \mathrm{AgNPs}+\mathrm{O}_{2}$

$\mathrm{H}_{2} \mathrm{O} \rightarrow \mathrm{H}^{+}+\mathrm{OH}$

$\mathrm{O}_{2}+\mathrm{H}^{-} \rightarrow \mathrm{HO}_{2}$

Silver nanoparticles $\left(\mathrm{e}_{C B}\right)+\mathrm{HO}_{2}+\mathrm{H}^{+} \rightarrow \mathrm{H}_{2} \mathrm{O}_{2}$

AgNPs $\left(\mathrm{h}^{+}{ }_{V B}\right)+$ dye $\rightarrow$ degradation products

$\mathrm{HO}^{-}+\mathrm{H}^{+} \rightarrow \mathrm{H}_{2} \mathrm{O}_{2}$

$\mathrm{HO}_{2}+\mathrm{e}^{-} \rightarrow \mathrm{HO}_{2}^{-}$

This indicates that the silver nanoparticles possess high photo degradation efficiency.

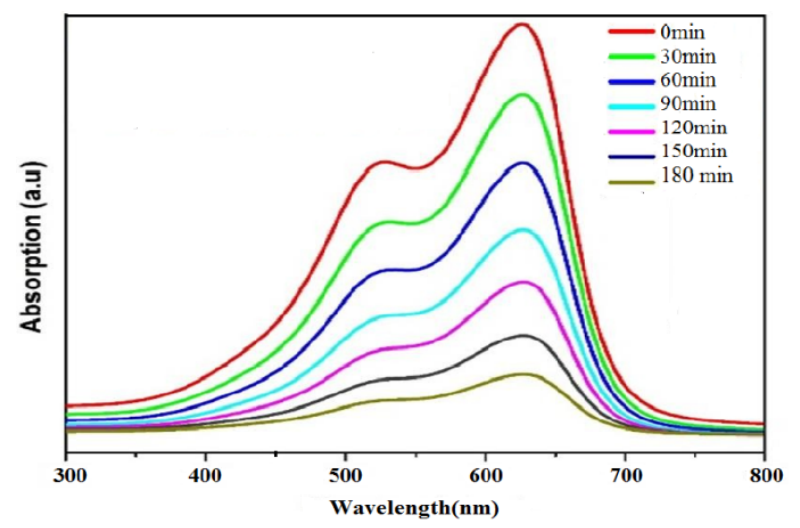

Fig 10. Time dependent absorption spectra

\subsection{Antibacterial activity}

Antibacterial assay of synthesized AgNPs against gram +ve and gram-ve bacteria at different concentrations were showed a strong properties of antibacterial agent for both tested microorganisms(Escherichia coli, Staphylococcus aureus) as shown in the Figure 11. It was absorbed that as the concentration of silver nanoparticles were greater the growth of the bacteria was less in both cases. Silver nanoparticles enhanced more antibacterial activity on gram-positive (Staphylococcus aureus) than gramnegative ones (Escherichia coli). Silver nanoparticles have contact with the cell surface of various bacteria. Many researchers have been reported the adhesion and accumulation of AgNPs to the bacteria surface. AgNPs can anchor to the bacterial cell wall and penetrate it and causing structural change in the cell membrane, i.e. increase the permeability and finally leads to the bacteria cell death. Karthi et al. ${ }^{(26)}$ have reported that there have been electron spin resonance spectroscopy studies that suggested that there is the information of free radicals with the bacterial action of AgNPs by the release of $\mathrm{Ag}^{+}$ions penetrate the +ve charge on the cell wall and ultimately leads to the cell death. The cells are made up of sulfur and phosphorus. The nanoparticles react to the components and destroyed. The antibacterial activity of AgNPs and the fisher's statistical reports are shown in Table 2. The results indicated that the AgNPs synthesized from Pathaneer have stronger antibacterial activity than $\mathrm{AgNo}_{3}$ and the standard antibiotic (Lysol). One of its high potential activities of Pathaneer is one of the alternates of tender coconut and it is also low-cost nanomedicine for fatigue, hair fall, obesity, nanomedicine constipation, Gastric ulcer and dry skin etc.

Each value is the mean of three replications each $(n=3)$. Statistically the means of the three experiments were not significantly 

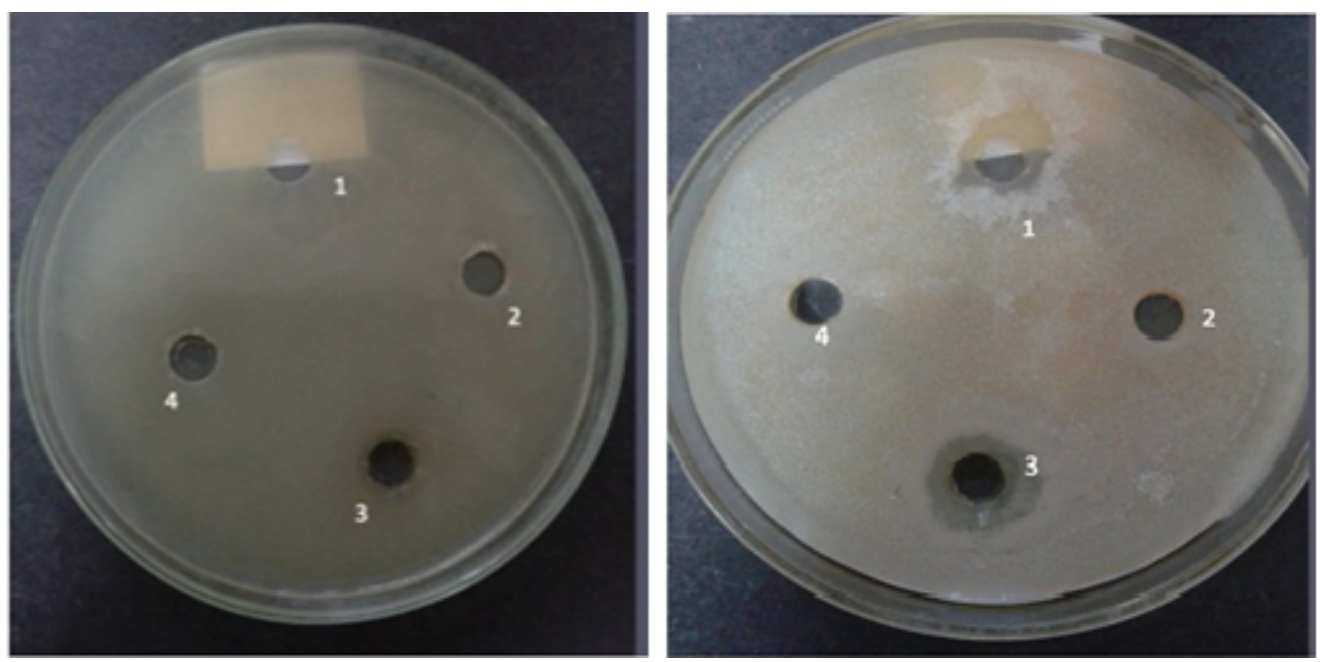

Fig 11. a. Escherichia coli, b. Staphylococcus aureus (Platephotos of AgNPs using Pathaneer)

Table 2. Antibacterial activity of AgNPs using Pathaneer

\begin{tabular}{lll}
\hline Compound & E.coli & S. aureus \\
\hline 1-Lyzol (1\%) & Nil & $12^{\mathrm{b}}$ \\
2-Negative control & Nil & Nil \\
$3-K M$ & $9^{\mathrm{a}}$ & $15^{\mathrm{a}}$ \\
$4-\mathrm{SKM}$ & $\mathrm{Nil}$ & $\mathrm{Nil}$ \\
\hline
\end{tabular}

different $(\mathrm{P}<0.05)$. Means in the same column with different letters are significantly different at $(\mathrm{P}<0.05)$ in accordance with Fisher's least significant difference test.

\section{Conclusion}

The synthesis of silver nanoparticles using Pathaneer was reported for the first time. In this synthesis no aggressive chemicals were used as reducing agent. Crystalline size and the structural morphology of the sample were analyzed using several types of instrumentation like XRD, Field Emission Scanning Electron Microscopy with Energy-dispersive X-ray spectroscopy and Dynamic light scattering. From the FTIR analysis, AgNPs were formed due to the biomolecular interaction. HRTEM exhibits the morphology distribution of AgNPs the optical band gap energy was derived from UV-Vis and fluorescence spectroscopy. The prepared AgNPs were proved as an effective photo catalytic degradation of MB dye under sunlight irradiation. Then it is found that the combination of Pathaneer with AgNPs enhances the antibacterial activity for Gram + ve and Gram -ve bacteria. It can be used as nanomedicine for constipation and Gastric ulcer etc.

\section{References}

1) J HH, T Y, S KW, H IS, et al. Highly reproducible polyol synthesis for silver nanocubes. J Cryst Growth. 2017;469:48-53.

2) Khatoon UT, Rao GVSN, Mohan KM, Ramanaviciene A, Ramanavicius A, et al. Antibacterial and antifungal activity of silver nanospheres synthesized by tri-sodium citrate assisted chemical approach. Vacuum. 2017;146:259-265. doi:10.1016/j.vacuum.2017.10.003.

3) Brobbey KJ, Haapanen J, Gunell M, Mäkelä JM, Eerola E, Toivakka M, et al. One step flame synthesis of silver nanoparticles for roll-to-roll production of antibacterial paper. Appl surfsci. 2017;420:558-565.

4) He R, Ren F, Chen F. Embedded silver nanoparticles in KTP crystal produced by ion implantation. Materials Letters. 2017;193:158-160. doi:10.1016/j.matlet.2017.01.119.

5) Dutta PP, Bordoloi M, Gogoi K, Roy S, Narzary B, Bhattacharyya DR, et al. Antimalarial silver and gold nanoparticles: Green synthesis, characterization and in vitro study. Biomedicine \& Pharmacotherapy. 2017;91:567-580. doi:10.1016/j.biopha.2017.04.032.

6) Singh T, Jyoti K, Patnaik A, Singh A, Chauhan R, Chandel SS, et al. Biosynthesis, characterization and antibacterial activity of silver nanoparticles using an endophytic fungal supernatant of Raphanus sativus. Journal of Genetic Engineering and Biotechnology. 2017;15(1):31-39. doi:10.1016/j.jgeb.2017.04.005.

7) der Horst CV, Silwana B, Iwuoha E, Somerset V, et al. Synthesis and Characterization of Bismuth-Silver Nanoparticles for Electrochemical Sensor Applications. Analytical Letters. 2015;48(8):1311-1332. doi:10.1080/00032719.2014.979357.

8) Saxena A, Tripathi RM, Zafar F, Singh P. Green synthesis of silver nanoparticles using aqueous solution of Ficus benghalensis leaf extract and 
characterization of their antibacterial activity. Materials Letters. 2012;67(1):91-94. Available from: https://dx.doi.org/10.1016/j.matlet.2011.09.038. doi:10.1016/j.matlet.2011.09.038.

9) Sunita D, Danai-Tambhale, Parag V, Adhyapak, et al. A facile Green synthesis of silver nanoparticles using Psoralea Corylifolia L. seed extract and their in- Vitro Antibacterial activities. Int J Pharma Bio Sci. 2014;5(1):457-467.

10) Henry F, Aritonang H, Koleangan AD, Wuntu, et al. Synthesis of Silver Nanoparticles Using Aqueous Extract of Medicinal Plants' (Impatiens balsamina and Lantana cama.ra) Fresh Leaves and Analysis of Antimicrobial Activity. International Journal of Microbiology. 2019. doi:10.1155/2019/8642303.

11) Nilesh S, Paul, Raman P, Yadav, et al. Biosynthesis of silver nanoparticles using plant seeds and their antimicrobial activity. Journal of Biomedical and Pharmaceutical Sciences. 2015;5(45):26-28. doi:10.15272/ajbps.v5i45.711.

12) Sekhar EC, Rao KSV, Rao K, Kumar SP, et al. A green approach to synthesize controllable silver nanostructures from Limonia acidissima for inactivation of pathogenic bacteria. Cogent Chemistry. 2016;2. Available from: http://dx.doi.org/10.1080/23312009.2016.1144296.

13) Nazeruddin GM, Prasad NR, Waghmare SR, Garadkar KM, Mulla IS, et al. Extracellular biosynthesis of silver nanoparticle using Azadirachta indica leaf extract and its anti-microbial activity. Journal of Alloys and Compounds. 2014;583:272-277. doi:10.1016/j.jallcom.2013.07.111.

14) Palanivelu J, Kunjumon AMM, Suresh A, Nair, Dr, Ramalingam C, et al. Green synthesis of silver nanoparticles from Dracaena mahatma leaf extract and its antimicrobial activity. J Pharm Sci \& Res. 2015;7(9):690-695.

15) Ahmad, Sharma S. Green synthesis of silvernanoparticles using extracts of Ananas comosus. Green and sustainable chemistry. 2012;2:141-147.

16) Karthik K, Dhanuskodi S, Gobinath C, Prabukumar S, Sivaramakrishnan S, et al. Multifunctional properties of CdO nanostructures Synthesised through microwave assisted hydrothermal method. Materials Research Innovations. 2019;23:310-318. doi:10.1080/14328917.2018.1475443.

17) Karthik K, Dhuskodi S. Structural and optical properties of microwave-assisted CdO-NiO nanocomposite. In: and others, editor. AIP Conf.Proc. 2016;p. 50021.

18) Sahai A, Goswami N. Structural and vibrational properties of $\mathrm{ZnO}$ nanoparticles synthesized by the chemical precipitation method. Physica E: Lowdimensional Systems and Nanostructures. 2014;58:130-137. doi:10.1016/j.physe.2013.12.009.

19) Maheshwari K, Saraswathi K, Sankari D, Arumugam P, et al. Evaluation of Bioactive chemical constituents by Gas chromatography-Mass spectrometry analysis isolated from Bacillus species. International Journal of Current Microbiology and Applied Sciences. 2016;5(11):488-497. doi:10.20546/ijcmas.2016.501.049.

20) Akhlaghi S, Kalalee M, Mazinani S. Effect of zinc oxide nanoparticles on isothermal cure kinetics, morphology and mechanical properties of EPDM rubber. Thermochim Acta. 2012;527:91-98.

21) Tatarchuk TR, Paliychuk ND, Bououdina M, Al-Najar B, Pacia M, Macyk W, et al. Effect of cobalt substitution on structural, elastic, magnetic and optical properties of zinc ferrite nanoparticles. Journal of Alloys and Compounds. 2018;731:1256-1266. Available from: https://dx.doi.org/10.1016/j.jallcom.2017. 10.103. doi:10.1016/j.jallcom.2017.10.103.

22) Babu BR, Tatarchuk T. Elastic properties and antistructural modeling for Nickel-Zinc ferrite-aluminates. Materials Chemistry and Physics. 2018;207:534541. Available from: https://dx.doi.org/10.1016/j.matchemphys.2017.12.084. doi:10.1016/j.matchemphys.2017.12.084.

23) Liu X, Atwater M, Wang J, Huo Q. Extinction coefficient of gold nanoparticles with different sizes and different capping ligands. Colloids and Surfaces B: Biointerfaces. 2007;58(1):3-7. Available from: https://dx.doi.org/10.1016/j.colsurfb.2006.08.005. doi:10.1016/j.colsurfb.2006.08.005.

24) Revathi V, Karthik K. Physico-chemical properties of semiorganic(Hexakis) Thiocarbamide nikel(II) nitrate single crystal. JEmerg Technol Innov Res. 2018;5(3):1035-2039.

25) Budhiraja N, Sharma A, Dahiya S, Parmar R, Vidyadharan V, et al. Synthesis and Optical Characteristics of Silver Nanoparticles on Different Substrates. International Letters of Chemistry, Physics and Astronomy. 2013;19:80-88. Available from: doi:10.18052/www.scipress.com/ILCPA.19.80.

26) Karthik K, Dhanuskodi S, Gobinath C, Prabukumar S, Sivaramakrishnan S, et al. Photocatalytic and antibacterial activities of hydrothermally prepared CdO nanoparticles. Journal of Materials Science: Materials in Electronics. 2017;28(15):11420-11429. doi:10.1007/s10854-017-6937-z. 